\title{
Quantifying Thermal Performance of the Building Envelope - Beyond Common Practice
}

\author{
Simon Pallin ${ }^{1}$, Jason W. DeGraw ${ }^{1}$, Mahabir Bhandari ${ }^{1}$ and Tyler Pilet $^{2}$ \\ ${ }^{1}$ Oak Ridge National Laboratory, Building Envelope \& Urban Systems Research Group, Energy and \\ Transportation Division, 1 Bethel Valley Rd, Oak Ridge, TN 37830, USA, pallinsb@ornl.gov \\ ${ }^{2}$ Georgia Institute of Technology, North Ave NW, Atlanta, GA 30332, USA, tpilet@gatech.edu
}

\begin{abstract}
Performance metrics serve as useful tools and indicators for many applications. For the building industry, various metrics exist; typically, these metrics do not assess the whole building performance. Instead, these represent separate components or heat transfer mechanisms of a building like $R$-value, $U$-factor/value, and airtightness. The mechanisms defined under these metrics all contribute significantly to the overall thermal performance of a building but will rarely act independently. There are metrics that account for the overall energy performance of a building, such as Energy Use Intensity (EUI). However, these metrics tend to be highly influenced by how the building is operated and used. There are also metrics which provide assessment on a relative basis. These indices are based upon comparison to a baseline, which complicates meaningful metric-based energy analyses. This paper presents a performance metric developed to account for various thermal properties and behaviors of a building. The metric accounts for all the relevant mechanisms that influence heat losses and gains in buildings and is thus directly related to the energy performance. In addition, the metric is designed to comprise air infiltration and allows users to account for workmanship quality, and imperfections of the building thermal resistance due to penetrations and other installations. This paper will describe how the metric can be applied for various building types and in different climates.
\end{abstract}

Keywords: BEP, Energy, Demand, Thermal Mass, Whole-Building.

\section{Introduction}

The thermal performance of a building depends on various building characteristics, including outdoor climate, building usage, HVAC equipment, occupants' indoor climate preferences, etc. Due to complex interaction between these variables, describing the thermal performance of a building is difficult. Many metrics exist to describe single variables, such as $R$-value, $U$-factor, airtightness (ACH50/75), Solar Heat Gain Coefficient (SHGC). However, none of these indicators can fully, or even realistically, solely describe the overall thermal performance.

Several attempts have been made to define metrics which account for most variables that possess a significant impact on the energy performance (Ferrari and Zanotto, 2016). Many of these efforts focus on the building envelope thermal mass, such as the TER (Reilly and Kinnane, 2017), the M-factor (Masonry Industry Committee, 1978; Yu, 1978), and the T-value (Alterman et al., 2012). Typically, the greatest hurdle to overcome is to account for solar loads and the impact it has on exterior building envelope surface temperatures and interior heat loads. The sol-air temperature (O'Callaghan and Probert, 1977) defines a fictious ambient temperature that accounts for solar induced heat transfer through the opaque building envelope, but that does not reflect solar induced interior heat gains.

There are also various simplified methods to calculate heating and cooling loads in buildings from estimating the overall thermal performance of buildings, such as CLTD/CLF (Spitler, 
McQuiston, and Lindsey, 1993) and the RTS method (ASHRAE, 2017). These methods include all variables relevant to the energy demand in buildings, including interior loads from solar radiation through windows. However, these methodologies do not result a single indicator that represents the whole building energy performance.

This paper proposes a simplified assessment that accounts for mechanisms relevant to the heat loss and gains through the building envelope and its impact on interior loads.

\section{Method}

This paper presents a methodology to assess the thermal performance of building using a singlevalued metric. The metric is based on the following principle.

$$
\begin{aligned}
& \frac{Q_{H V A C}}{\eta}=Q_{n e t}^{e n v} \\
& Q_{n e t}^{e n v}=B E P \cdot A_{\text {tot }}^{e n v}
\end{aligned}
$$

The HVAC energy demand (no internal loads), $Q_{\text {HVAC }}(\mathrm{J}[\mathrm{Btu}])$, will mainly depend on the efficiency of the HVAC system $\eta(-)$ and the net building envelope heat transfer $Q_{\text {net }}^{\text {env }}(\mathrm{J}[\mathrm{Btu}])$. In Eq. (1), we introduce the Building Envelope Performance metric, BEP $\left(\mathrm{J} / \mathrm{m}^{2}\left[\mathrm{Btu} / \mathrm{ft}^{2}\right]\right)$, which is defined by the overall building envelope thermal load per building envelope area, $A_{\text {tot }}^{e n v}$. For

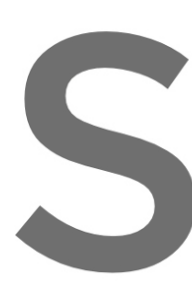
annual heating and co envelope component heating (h) degree convection and radiatior
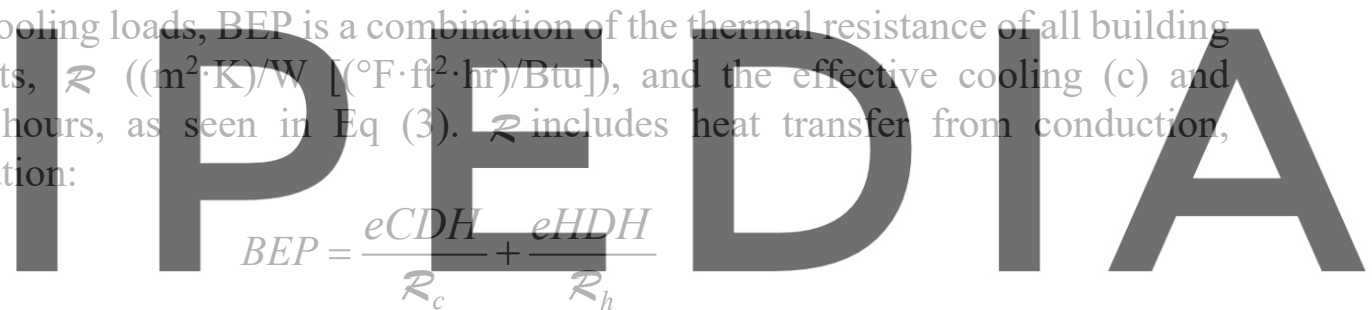

Register for free at https//www.scipedia.com to download the version without the watermark

$$
\overline{\sigma \cdot R_{\text {env }}}+\overline{R_{\text {air }}}+\overline{R_{\text {gain }}}
$$

where

$e C D H=$ Effective cooling degree hours $\left(\mathrm{K} \cdot \mathrm{hr}\left[{ }^{\circ} \mathrm{F} \cdot \mathrm{hr}\right]\right)$,

$e H D H=$ Effective heating degree hours $\left(\mathrm{K} \cdot \mathrm{hr}\left[{ }^{\circ} \mathrm{F} \cdot \mathrm{hr}\right]\right)$,

$R_{e n v}=$ Conductive thermal resistance, $R$-value $\left(\left(\mathrm{m}^{2} \cdot \mathrm{K}\right) / \mathrm{W}\left[\left({ }^{\circ} \mathrm{F} \cdot \mathrm{ft}^{2} \cdot \mathrm{hr}\right) / \mathrm{Btu}\right]\right)$,

$R_{\text {air }}=$ Air leakage resistance $\left(\left(\mathrm{m}^{2} \cdot \mathrm{K}\right) / \mathrm{W}\left[\left({ }^{\circ} \mathrm{F} \cdot \mathrm{ft}^{2} \cdot \mathrm{hr}\right) / \mathrm{Btu}\right]\right)$,

$R_{\text {gain }}=$ Window solar and internal heat gains resistance $\left(\left(\mathrm{m}^{2} \cdot \mathrm{K}\right) / \mathrm{W}\left[\left({ }^{\circ} \mathrm{F} \cdot \mathrm{ft}^{2} \cdot \mathrm{hr}\right) / \mathrm{Btu}\right]\right)$,

$\sigma \quad=$ Opaque envelope solar and thermal radiation correction factor (-).

$e C D H$ and $e H D H$ are calculated from average outdoor and indoor temperatures during cooling and heating mode respectively.

$$
\begin{aligned}
& e C D H=\left(T_{\text {out }}^{\text {avg }, c}-T_{\text {in,cool }}\right) \cdot t_{\text {cool }} \\
& e H D H=\left(T_{\text {in, heat }}-T_{\text {out }}^{\text {avg } h}\right) \cdot t_{\text {heat }}
\end{aligned}
$$


Here,

$T_{\text {out }}^{\text {avg } c-h}=$ Average outdoor temperature during cooling (c) or heating $(\mathrm{h})\left(\mathrm{K}\left[{ }^{\circ} \mathrm{F}\right]\right)$,

$T_{\text {in,cool }}=$ Indoor setpoint temperature for cooling $\left(\mathrm{K}\left[{ }^{\circ} \mathrm{F}\right]\right)$,

$T_{\text {in,heat }}=$ Indoor setpoint temperature for heating $\left(\mathrm{K}\left[{ }^{\circ} \mathrm{F}\right]\right)$,

$t_{\text {cool }}=$ Time for which cooling occurs (hr),

$t_{\text {heat }}=$ Time for which heating occurs (hr).

Note that the effective cooling and heating degree hours defined in Eq. (3) are not the same as regular cooling and heating degree hours (Erbs, Klein, and Beckman, 1984). For example, because of heat loads (solar and internal), cooling may occur when the ambient outdoor temperature is below the indoor cooling setpoint temperature. Defining effective degree hours are essential to account for all loads/sinks contributing to the HVAC running cycle.

\subsection{Conductive Heat Transfer}

The resulting building envelope $R$-value, $R_{e m,}$, is expressed as:
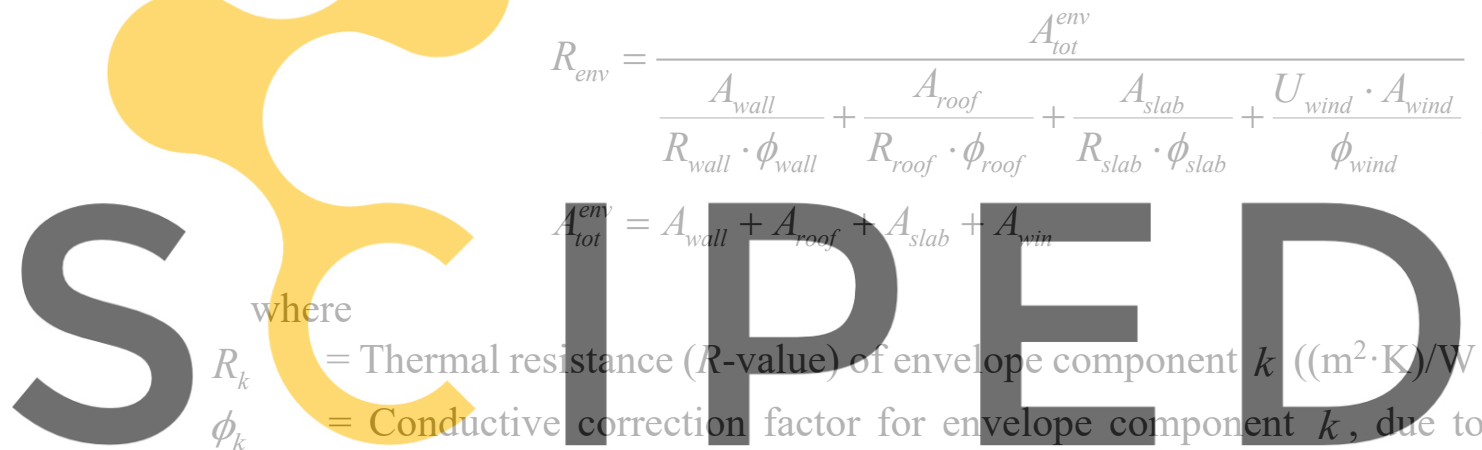

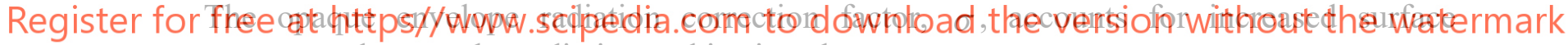
temperatures due to solar radiation and is given by:

$$
\sigma=\frac{T_{o u t}^{\text {avg }}-T_{\text {in }}}{T_{e q}-T_{\text {in }}},
$$

where

$$
T_{e q}=\frac{T_{e q}^{\text {roof }} \cdot A_{\text {roof }}+T_{e q}^{\text {wall }} \cdot A_{\text {wall }}+T_{\text {out }}^{\text {avg }}\left(A_{\text {win }}+A_{\text {slab }}\right)}{A_{\text {tot }}^{\text {env }}},
$$

In which, 


$$
\begin{aligned}
& T_{e q}^{\text {wall }}=T_{\text {out }}^{\text {avg }}+R_{\text {se }, \text { wall }}\left(\alpha_{\text {wall }}\left(\frac{I_{\text {sol }, E}^{\text {avg }} \cdot A_{\text {wall }, E}+I_{\text {sol }, S}^{\text {avg }} \cdot A_{\text {wall }, S}+I_{\text {sol }, W}^{a v g} \cdot A_{\text {wall }, W}+I_{\text {sol }, N}^{\text {avg }} \cdot A_{\text {wall }, N}}{A_{\text {wall }}}\right)\right. \\
& \left.+\frac{I_{\text {sky }, E}^{\text {vvg }} \cdot A_{\text {wall }, E}+I_{\text {sky }, S}^{\text {avg }} \cdot A_{\text {wall }, S}+I_{\text {sky }, W}^{\text {avg }} \cdot A_{\text {wall }, W}+I_{\text {sky }, N}^{\text {avg }} \cdot A_{\text {wall }, N}}{A_{\text {wall }}}\right) \\
& T_{e q}^{\text {roof }}=T_{\text {out }}^{\text {avg }}+R_{\text {se }, \text { roof }}\left(\alpha_{\text {roof }} \cdot I_{\text {sol }, h o r}^{\text {avg }}+I_{\text {sky }, h o r}^{\text {avg }}\right)
\end{aligned}
$$

and

$T_{e q} \quad=$ Equivalent building envelope surface temperature $\left(\mathrm{K}\left[{ }^{\circ} \mathrm{F}\right]\right)$,

$T_{\text {out }}^{\text {avg }}=$ Average outdoor temperature when either cooling or heating occurs $\left(\mathrm{K}\left[{ }^{\circ} \mathrm{F}\right]\right)$,

$I_{\text {sol, }, j}^{\text {avg }}=$ Annual average incident solar radiation on vertical surface in direction $j$ $\left(\mathrm{W} / \mathrm{m}^{2}\left[\mathrm{Btu} /\left(\mathrm{hr} \cdot \mathrm{ft}^{2}\right)\right]\right)$,

$I_{s k v, j}^{a v g}=$ Annual average infrared radiation on vertical surface in direction $j$ $\left(\mathrm{W} / \mathrm{m}^{2}\left[\mathrm{Btu} /\left(\mathrm{hr} \cdot \mathrm{ft}^{2}\right)\right]\right)$

$I_{\text {sol, vert }}^{\text {avg }}=$ Annual average incident solar radiation on vertical surfaces $\left(\mathrm{W} / \mathrm{m}^{2}\left[\mathrm{Btu} /\left(\mathrm{hr} \cdot \mathrm{ft}^{2}\right)\right]\right)$,

$I_{s k y, v e r t}^{a v g}=$ Annual average infrared radiation on vertical surfaces $\left(\mathrm{W} / \mathrm{m}^{2}\left[\mathrm{Btu} /\left(\mathrm{hr} \cdot \mathrm{ft}^{2}\right)\right]\right)$,
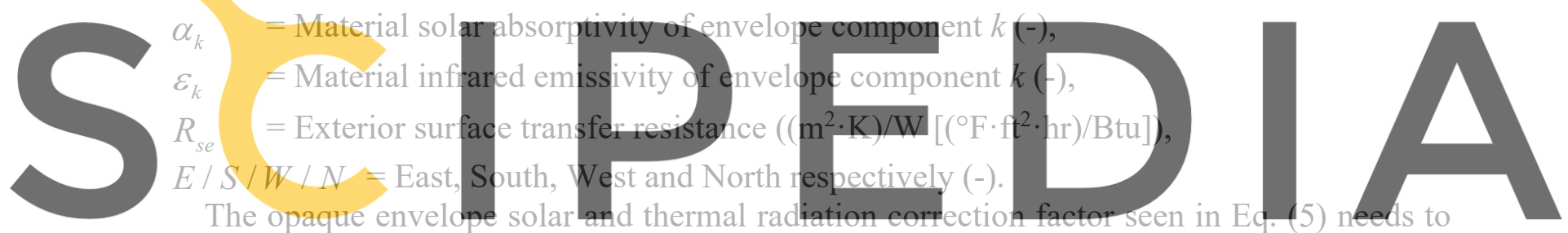

be calculated for both heating $\left(t_{\text {tho }}>0\right)$ and cooling $\left(t_{\text {on }}>0\right)$ since $T_{\text {o }}$ and $T_{\text {ovg }}^{\text {varies }}$

Register for free at https//www.scipedia.com to download the version without the watermark

$$
\sigma^{c}=\frac{T_{\text {out }}^{\text {avg }, c}-T_{\text {in,cool }}}{T_{e q}^{c}-T_{\text {in,cool }}} \text { and } \sigma^{h}=\frac{T_{\text {out }}^{\text {avg } h}-T_{\text {in,heat }}}{T_{e q}^{h}-T_{\text {in, heat }}} .
$$

\subsection{Convective Heat Transfer}

The effective thermal resistance due to air infiltration through the building envelope, $R_{a i r}$, is defined as:

$$
\begin{aligned}
R_{a i r} & =\frac{A_{t o t}^{e n v}}{\overline{\dot{V}} \cdot \rho_{\text {air }} \cdot c_{\text {air }}} \\
\overline{\dot{V}} & =C \cdot(\overline{\Delta P})^{n}
\end{aligned}
$$

Where

$\overline{\dot{V}} \quad=$ Annual average air flow rate through the building envelope during either cooling or 


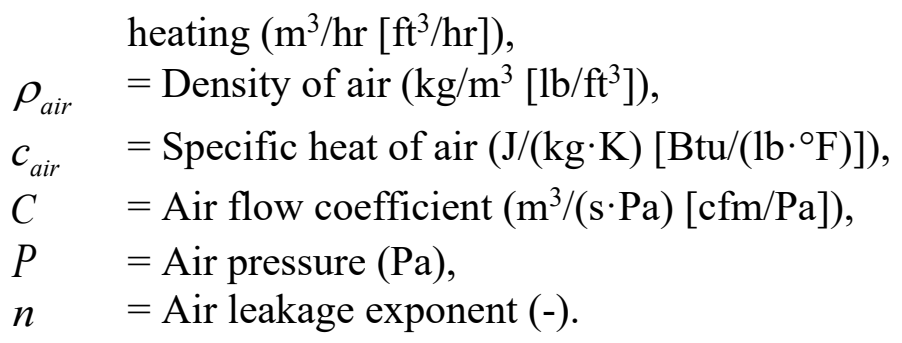

The average air pressure difference is calculated during the time of either cooling or heating. Typically, the overall pressure gradient, $\Delta P$, around the building envelope is the sum of three components; wind loads, $\Delta P_{w}$, buoyancy effect (stack), $\Delta P_{s}$, and ventilation, $\Delta P_{v}$.

$$
\Delta P=\Delta P_{w}+\Delta P_{s}+\Delta P_{v}
$$

As for all variables in Eq. (2), $R_{\text {air }}$ is defined for either cooling or heating.

\subsection{Solar, Thermal and Internal Heat Gains}

Finally, an effective thermal resistance is found, due to interior heat loads. These loads consist of solar and thermal radiation through windows and all interior loads from equipment, appliances, lighting, humans, etc. The heat gain resistance, $R_{\text {gain }}$, is written as
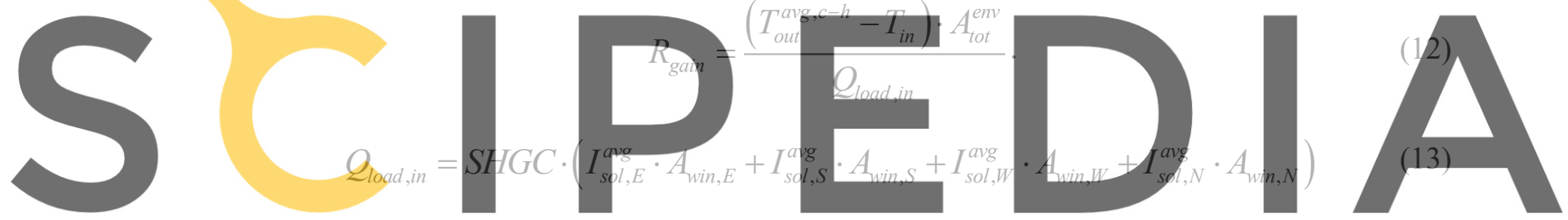

where

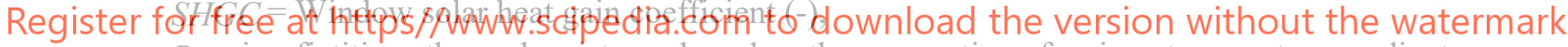
$R_{\text {gain }}$ is a fictitious thermal resistance based on the assumption of a given temperature gradient,

$\left(T_{\text {out }}^{\text {avg } c-h}-T_{\text {in }}\right)$, which allows all thermal resistances in Eq. (2) to be lumped together.

\section{Result}

The proposed BEP metric of this paper has been validated against transient energy modelling simulation tools (EnergyPlus, 2018). The simulated building was setup as a rectangular building and with characteristics described in Table 1.

The overall heating and cooling demands were computed for 16 different U.S. climate zones (IECC, 2015) and the indoor temperature was kept at $20^{\circ} \mathrm{C}\left[68^{\circ} \mathrm{F}\right]$. As seen in Eq. (2), BEP relies on the effective heating and cooling degree hours. These hours are calculated based on all loads contributing to the indoor temperature. In general, cooling and heating degree hours are calculated under the following conditions:

$$
\begin{aligned}
& \text { eCDH when } Q_{\text {net }}^{\text {cool }}>0 \\
& \text { eHDH when } Q_{\text {net }}^{\text {heat }}<0
\end{aligned}
$$




$$
\begin{aligned}
& Q_{\text {net }}^{\text {cool }}=\boldsymbol{R} \cdot\left(T_{\text {out }}^{\text {avg }, c}-T_{\text {in, cool }}\right) \cdot A_{\text {tot }}^{\text {env }} \\
& Q_{\text {net }}^{\text {heat }}=\boldsymbol{R} \cdot\left(T_{\text {in }, \text { heat }}-T_{\text {out }}^{\text {avg }, h}\right) \cdot A_{\text {tot }}^{\text {env }}
\end{aligned}
$$

Table 1. Simulation model used to validate the BEP metric.

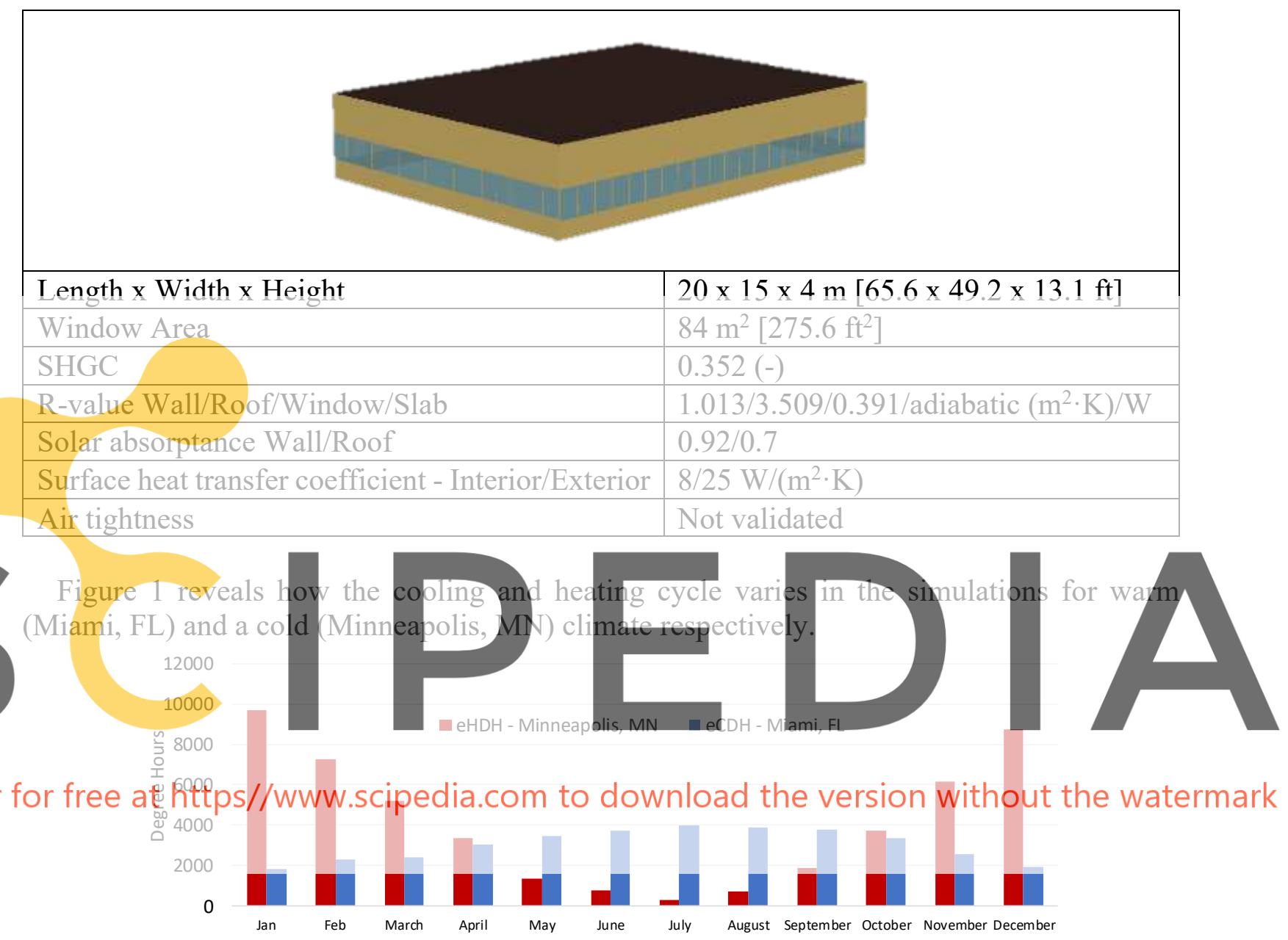

Figure 1. Variation in effective heating and cooling degree hours between a hot (Miami, FL) and cold (Minneapolis, $\mathrm{MN}$ ) climate. $e \mathrm{CDH}$ and $e H D H$ are calculated in accordance with Eq. (15).

A comparison was made for BEP between various comprehensive simulation models (EnergyPlus, 2018; IBP, 2019; van Dijk, Spiekman, and Hoes-van Oeffelen, 2016). Figure 2 depicts simulated cooling and heating demand for 16 locations in the U.S. According to this result, the BEP shows good agreement with more sophisticated simulation models. The main reason to the discrepancies depicted in Figure 2 for the simulated heating and cooling demand seems to be a result of dissimilar approaches to compute heat surface film coefficients.

As previously discussed, the BEP metric will account for various variables that are dependent on exterior climate conditions. Figure 3 reveals the variation of BEP for various climates. According to the figure, colder climates tend to require an overall greater energy demand, thus a higher value of BEP. 


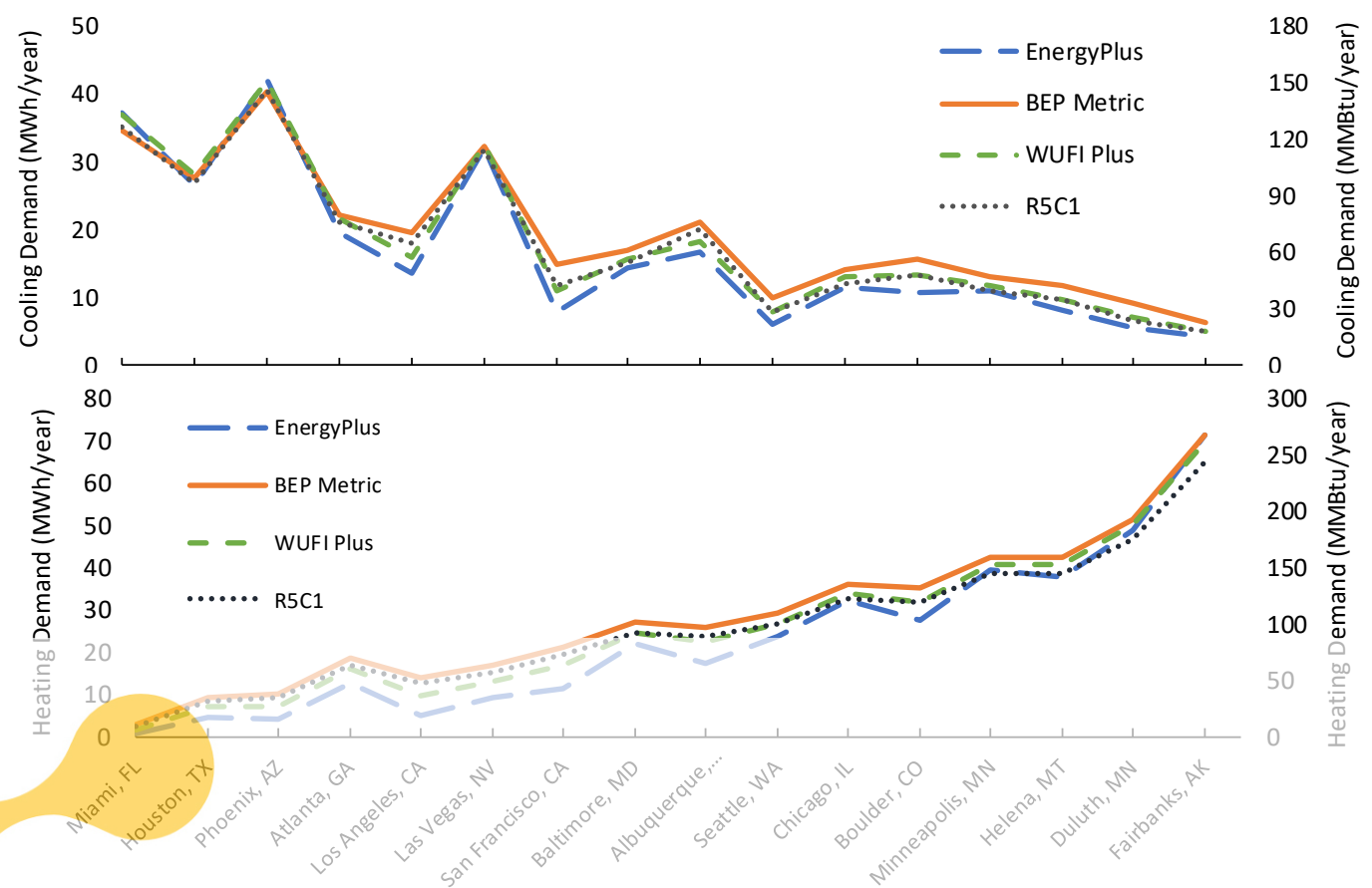

Figure 2. Validation between the proposed metric, EnergyPlus, R5C1, and finite element simulations. The proposed metric shows good agreement with more sophisticated simulation procedures.
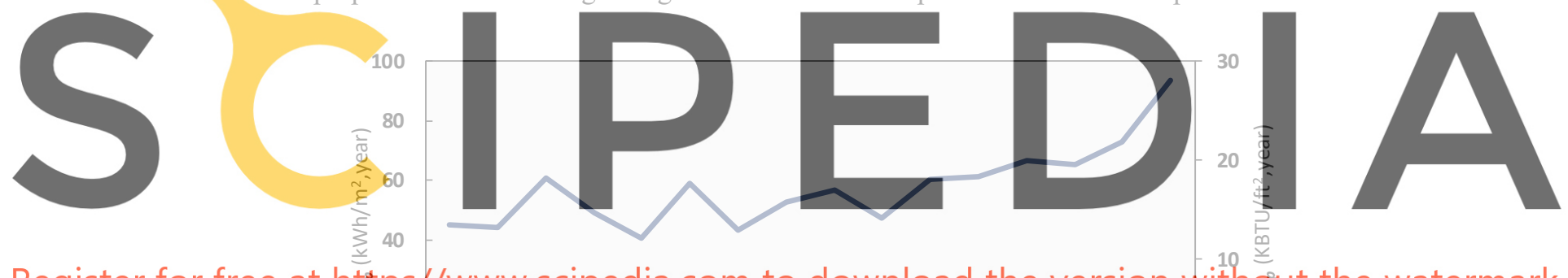

Register for free at hțps//www.scipedia.com to download the version with

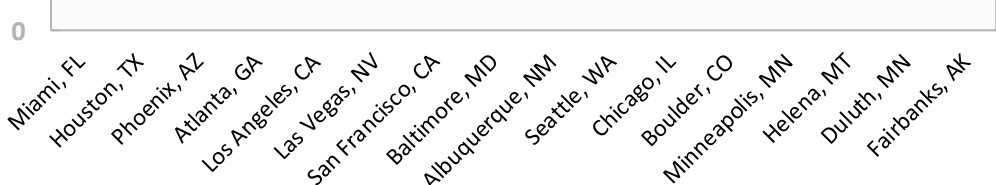

Figure 3. Variation in BEP between 16 different locations and U.S. climate zones for the validated building.

\section{Conclusions}

This paper introduces a new building envelope thermal performance metric, BEP. The metric accounts for all relevant heat transfer mechanisms affecting the energy demand of a building due to outdoor climate and interior thermal loads; conductive heat transfer, air infiltration, solar heat gains affecting opaque building envelope surface temperatures and indoor heat loads. This paper also presents an initial validation study by comparing simulation results from various whole building energy simulation tools. According to the comparison, BEP can predict overall energy performance similarly to existing simulation tools.

The purpose and advantage of BEP are that it does not require an iterative simulation 
procedure. Instead, the proposed metric relies on input data given by the geometry of the building, thermal characteristics and outdoor climate date. This feature allows for a quick, yet accurate, thermal performance assessment of a building.

Lastly, BEP serves as an overall building envelope thermal performance metric. This allows for easy comparison of the thermal performance of buildings with varying building type, characteristics, and climate location. Additionally, the BEP allows for efficient comparison of the predicted energy performance of planned retrofits.

\section{Acknowledgements}

This manuscript has been authored by UT-Battelle LLC under contract DE-AC05-00OR22725 with the US Department of Energy (DOE). The US government retains and the publisher, by accepting the article for publication, acknowledges that the US government retains a nonexclusive, paid-up, irrevocable, worldwide license to publish or reproduce the published form of this manuscript, or allow others to do so, for US government purposes. DOE will provide public access to these results of federally sponsored research in accordance with the DOE Public Access Plan (http://energy.gov/ downloads/doe-public-access-plan).

ORCIID

Simon Pallin: https://orcid.org/0000-0001-7197-6746

Mahabir Bhandari: https://orcid.org/0000-0003-1951-9876

Tyler Pilet: https://orcid.org/0000-0001-9680-6866

References

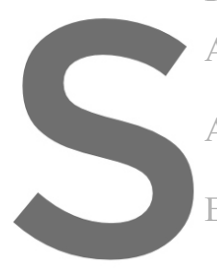

Alterman, D., Moffiet, T to characterise the dyn

ASHRAE. (2017). ASHR Calculations. America

EnergyPlus. (2018 https:/energyplus.net/sites/all/modiles/custom/nre
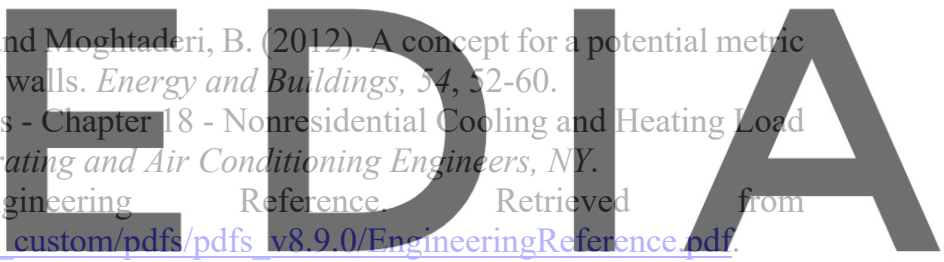

Erbs, D. G., Klein, S. A. and Beckman, W. A. (1984). Sol-air heating and cooling degree-days. Solar Energy,

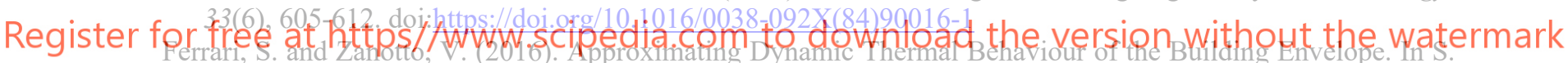
Ferrari \& V. Zanotto (Eds.), Building Energy Performance Assessment in Southern Europe, 21-33. Cham: Springer International Publishing.

IBP, F. (2019). Wufi Plus - Software for calculating three dimensional coupled heat and moisture transfer in building components. Retrieved from http://www.wufi.de/index e.html

IECC. (2015). International Energy Conservation Code - Residential Energy Efficiency. In. Country Club Hills, IL, USA: International Code Council, Inc.

Masonry Industry Committee. (1978). the " $m$ " factor: The use of mass to save energy in heating and cooling of buildings. Retrieved from Masonry Industry Committee:

O'Callaghan, P. W. and Probert, S. D. (1977). Sol-air temperature. Applied Energy, 3(4), $307-311$. doi:https://doi.org/10.1016/0306-2619(77)90017-4

Reilly, A and Kinnane, O. (2017). The impact of thermal mass on building energy consumption. Applied Energy, 198, 108-121. doi:https://doi.org/10.1016/j.apenergy.2017.04.024

Spitler, J., McQuiston, F. and Lindsey, K. (1993). CLTD/SCL/CLF cooling load calculation method. Paper presented at the the 1993 Winter Meeting of ASHRAE Transactions. Part 1, Chicago, IL, USA, 01/23-27/93.

van Dijk, H., Spiekman, M. and Hoes-van Oeffelen, E. (2016). EPB standard EN ISO 52016: calculation of the building's energy needs for heating and cooling, internal temperatures and heating and cooling load.

Yu, H. C. (1978). The M Factor: A New Concept in Heat Transfer Calculations. Consulting Engineer, 1978. 